\title{
Significados da imagem de intelectual para a construção da identidade do jornalista
}

\section{Fernanda Lima Lopes}

\section{Resumo}

Embora Gramsci e Bourdieu resistam em considerar os jornalistas intelectuais, a identidade jornalística está impregnada dessa noção. Resta questionar, então, que tipo de intelectuais eles são, visto que existem diferentes categorias em que eles podem se enquadrar, segundo as tipologias desenvolvidas por autores clássicos como Sartre, Gramsci e Bobbio. Ao tratar da imagem de intelectual na construção da identidade do jornalista no mundo contemporâneo, é de suma importância considerar, ainda, o lugar e o papel do intelectual frente à lógica das novas tecnologias de informação e comunicação, tarefa que conta com a ajuda das reflexões de pensadores como Edward Said, Beatriz Sarlo e Octavio Ianni.

Palavras-chave

Jornalista. Intelectual. Identidade.

\section{Fernanda Lima Lopes I ferdynanda@yahoo.com}

Universidade Federal do Rio de Janeiro. Doutoranda em Comunicação e Cultura pela UFRJ. Mestre em Comunicação e Cultura pela UFRJ (fev-2007), possui graduação em Comunicação Social-Jornalismo pela UFMG (abr-2003). Tem experiência na área de Comunicação, com ênfase em Jornalismo, principalmente nos seguintes temas: identidade, memória, representações sociais, técnicas jornalísticas, história do jornalismo, teorias do jornalismo, estudos da linguagem, semiótica, novas tecnologias de informação e comunicação, discussões sobre a contemporaneidade. Atuou como professora de Semiótica no curso de Comunicação Social do Unileste/MG. Foi jornalista responsável pelo setor de comunicação da Escola Educação Criativa (Ipatinga/MG), tendo trabalhado com produção editorial (livros e outras publicações impressas), site e assessoria de comunicação.

\section{Introdução}

Em minhas experiências como docente no curso de jornalismo, costumava iniciar o contato com a turma, dirigindo aos alunos a pergunta: "por que você escolheu esse curso?" No fundo, para mim, a pergunta queria dizer: 0 que move alguém a ser jornalista no país atualmente? Essa sondagem informal sobre as imagens que os recém chegados à universidade fazem a respeito dessa profissão insere-se num contexto maior de uma pesquisa mais abrangente, cujo objetivo é investigar a identidade do jornalista no Brasil da contemporaneidade. Tema de dissertação de mestrado (LOPES, 2007), continuo a desenvolver tal pesquisa e aprofundá-la no doutorado.

Este trabalho representa uma parcela das reflexões que procuram dar conta das variadas representações que esse profissional apresenta no espaço social em que ele se insere. Sabendo do importante lugar ocupado pelo jornalista nos tradicionais e novos meios de comunicação, e considerando suas estratégias discursivas e posicionamentos sociais no desempenho de suas funções, busca-se, aqui, elucidar alguns sentidos 
e imagens construídos a partir da percepção do jornalista como um intelectual.

Uma certa imagem ligada às ideias de inteligência, cultura e envolvimento social aparece projetada não só na fala dos alunos que escolhem fazer jornalismo, mas também em diversos outros discursos, inclusive dentro da própria mídia, local de trabalho de grande parte da categoria jornalística. De fato, é possível considerar que a identidade do jornalista está impregnada de elementos capazes de caracterizá-los como intelectuais. Seu trabalho essencialmente textual, o contato que possuem com os mais diversos ramos do conhecimento, 0 espaço que ocupam nos meios de comunicação, juntamente com sua autoridade de falar ao mundo são dados que ajudam a formar representações aproximadas de uma dada noção de intelectual.

Por outro lado, contudo, é possível verificar entre alguns importantes estudiosos do mundo social uma explícita resistência em considerar os jornalistas como intelectuais. Antonio Gramsci, por exemplo, diz: "0 tipo tradicional e vulgarizado do intelectual é fornecido pelo literato, pelo filósofo, pelo artista. Por isso, os jornalistas - que creem ser literatos, filósofos e artistas - creem também ser os 'verdadeiros' intelectuais" (GRAMSCI, 1988, p. 8). Bourdieu, que dedica um livro a fazer sérias críticas ao poder de dominação que a televisão exerce no mundo atual (1997), também se mostra incomodado com o fato de os jornalistas, ocupantes privilegiados do espaço televisivo, se autodenominarem intelectuais. Ele escreve:

$$
\begin{aligned}
& \text { E eles podem desviar uma parte desse poder } \\
& \text { de consagração em seu proveito (o fato de que } \\
& \text { os jornalistas estão, mesmo os mais reconheci- } \\
& \text { dos, em posição de inferioridade estrutural com } \\
& \text { relação a categorias que eles podem dominar } \\
& \text { ocasionalmente, como os intelectuais - entre os } \\
& \text { quais eles ardem por classificar-se - e os polí- } \\
& \text { ticos, contribui, sem dúvida, para explicar sua } \\
& \text { tendência constante ao anti-intelectualismo). } \\
& \text { (BOURDIEU, 1997, p. 66) }
\end{aligned}
$$

Tendo em vista essas discrepâncias, este artigo também fará um esforço de reflexão sobre os critérios para se considerar alguém um "verdadeiro intelectual" ou um intelectual de outra espécie. Autores clássicos como Sartre, Gramsci e Bobbio fornecem classificações sobre as tipologias de intelectuais, sempre levando em conta não características intrínsecas a eles, mas sim desenvolvendo tais categorias a partir de um olhar para a existência concreta. E, como a preocupação central é pensar a identidade do jornalista no mundo contemporâneo, é de suma importância refletir sobre sua representação como intelectual com a ajuda de autores que pensam o lugar e o modo de atuação dos diferentes tipos de intelectuais frente à lógica das novas tecnologias de informação e comunicação. Para isso, são preciosas as contribuições de Edward Said, Beatriz Sarlo e Octavio Ianni.

\section{Alguns tipos de intelectual}

De maneira geral, o intelectual é normalmente identificado como uma pessoa cujas atividades 
dependem mais de habilidades mentais do que físicas. Assim, associa-se que tal indivíduo possui um alto nível de escolaridade, demonstra ter acumulado bastante conhecimento, não só na sua área de formação, mas também em outras. Acredita-se que um intelectual tem capacidade de articular bem as palavras, tanto na escrita quanto na fala; ele é visto como uma pessoa inteligente, erudita, culta, competente. Ordinariamente são essas e outras ideias que fazem parte de uma certa imagem de distinção do qual o intelectual está revestido.

Contudo, há tantas maneiras de o ser humano usar sua inteligência, há tantas atividades que exigem pessoas com as mais variadas formações, há tantos diferentes saberes e tantas formas de aplicá-los que não há como conceber que todos os intelectuais sejam de um mesmo tipo. Como veremos a seguir, existe uma lista de diferentes maneiras de ser um intelectual. Para além da exposição da tipologia de intelectuais (que certamente nos serão importantes para embasar a discussão sobre a imagem dos jornalistas como intelectuais), é possível perceber que alguns autores defendem o que poderia ser tomado como 0 "verdadeiro intelectual". Em seus textos, acabam por estabelecer, de uma forma ou de outra, parâmetros e critérios para um modelo ideal.

Uma das mais conhecidas caracterizações acerca dos intelectuais é fornecida por Antonio Gramsci. Tendo em vista o processo histórico de formação dos mesmos, 0 autor indica dois tipos: tradicionais e orgânicos. A classificação "tradicionais" é aplicada a grupos que remontam a épocas anteriores à estruturação do capitalismo, como o dos eclesiásticos ou dos médicos, por exemplo, grupos de indivíduos reunidos em torno de suas competências, saberes, qualificações específicas que lhes garantia prestígio e autonomia frente à classe dominante. A existência dos intelectuais tradicionais funda-se na diferenciação dos membros desse grupo em relação aos homens comuns em virtude da posse de saberes especializados e poderes tidos como especiais. Segundo Gramsci (1988), essa categoria tem origens remotas: na Roma antiga, por exemplo, o governador César concedeu cidadania romana a médicos e mestres das artes liberais, numa atitude de reconhecimento de suas capacidades.

Já em relação aos intelectuais orgânicos, seu aparecimento está historicamente localizado à organização do capitalismo e à consolidação do poder de dominação da burguesia na sociedade dividida em classes. Tal como explica Gramsci, a formação industrial proporcionou não só a estratificação social segundo lugares ocupados nas funções produtivas, mas permitiu o surgimento de um grupo de intelectuais cujas atividades e cujos saberes não significavam autonomia e independência, mas um atrelamento e prestação de serviço a algum outro grupo ou classe. Mas não uma 
prestação de serviço qualquer, como os trabalhos da classe operária, ou mesmo dos técnicos mais especializados, mas também meros fornecedores de mão-de-obra para a produção. Ao grupo dos intelectuais orgânicos correspondiam as atribuições de disciplinar e orientar as funções no mundo produtivo; ou seja, eles exerceriam atividades capazes de organizar a sociedade em geral, criando condições favoráveis para 0 crescimento desse grupo ou classe. Nos dizeres de Gramsci, seriam como '“comissários' do grupo dominante para o exercício de funções subalternas da hegemonia social e do governo político" (1988, p. 11). 0 intelectual orgânico, portanto, não é ele mesmo o poder dominante, nem sequer pode ser visto como simples representante ou porta-voz de uma classe ou grupo. Ele é aquele que - por meio de suas funções realizadas no contexto das relações sociais que se dão na sociedade civil - promove condições para a construção da hegemonia de um grupo ou classe. (Essa classificação de intelectual concebida por Gramsci é bastante interessante para pensar modos de atuação dos jornalistas, já que tal noção enfatiza a propriedade do intelectual orgânico em funcionar como um agente organizador da cultura. Isso será tratado mais à frente).

A tipologia gramsciana de "intelectuais orgânicos" apresenta alguns pontos de semelhanças com um tipo de intelectual ao qual Jean Paul Sartre denominou "especialista do saber prático" (1994, p. 18): ambas classificações tratam de um intelectual ligado ao desenvolvimento da burguesia e as duas comungam uma atitude de não-questionamento à ordem vigente, mas uma plena imersão na lógica dominante por meio da realização de suas atividades que os reitera como "servidores da hegemonia" (SARTRE, 1994, p. 23).

Na verdade, Sartre sequer admite considerar o técnico do saber prático como intelectual, pois, a seu ver, a notoriedade conseguida pelo desempenho de trabalhos que usam a inteligência não é critério para caracterizar um verdadeiro intelectual. Aquele é classificado, então, por Sartre, como um "especialista", ou seja: um indivíduo dotado de saber técnico, que faz uso de seus conhecimentos e envolvese em pesquisas no intuito de contribuir para o desenvolvimento dos meios de produção. Os conhecimentos que acumula são provenientes de anos da formação ideológica e técnica que recebeu no sistema escolar constituído pela classe dominante. Aliás, esse especialista é recrutado dela (muitas vezes são filhos de burgueses, mas que acabam assumindo outro papel como especialistas), mas não é um fiel exemplar de tal classe, isto é, não ocupa a mesma posição na dinâmica da práxis produtiva. Ele está, por seu trabalho intelectual e técnico, imerso na organização e manutenção dos meios de produção, mas não toma parte nos seus fins. "Os fins são definidos pela classe dominante e realizados pelas classes trabalhadoras" (SARTRE, 1994, p. 17). 0 técnico do saber 
prático, então, fica no meio, contribuindo, com seu serviço, para reproduzir - e às vezes aprimorar - a lógica de funcionamento da sociedade na qual foram formados. E, nesse sentido, porque comprometem seu saber e sua competência em favor do desenvolvimento de mecanismos que sustentam o status quo funcionam como "guardiães da tradição" (SARTRE, 1994, p. 23).

Essas noções válidas para 0 técnico do saber prático também podem ser trazidas para 0 entendimento do termo "experto", usado por Norberto Bobbio para descrever o tipo de intelectual que age como "conselheiro do príncipe" (1997, p. 73), isto é, aquele que possui seus conhecimentos especializados e os usa para alcançar um objetivo. Pragmático, ele não está preocupado com valores e princípios, mas com a promoção de resultados, por isso, investe seus saberes técnicos para lidar com os meios necessários que o levem a atingir um determinado fim. Contudo, não se envolve na discussão sobre a validade ideológica desse fim. Nesse sentido, são apenas transmissores de ideias e não criadores delas ${ }^{1}$.

Há nessas classificações de Gramsci, Sartre e Bobbio um certo tom de crítica àqueles que usam suas faculdades mentais, seus conhecimentos, sua formação, sua educação, para, de alguma forma, contribuir para a sustentação da hegemonia da classe dominante. Mas há uma expectativa, sobretudo mais claramente em Sartre e Bobbio, de que uma outra postura deve ser tomada por um intelectual genuíno. Sartre (1994) defende que um intelectual do tipo agente do saber prático pode vir a se tornar um intelectual de fato caso passe por uma tomada de consciência. Para ele, alguém se torna um verdadeiro intelectual quando é capaz de contestar o mundo e a si mesmo:

[...] se ele se recusa a ser agente subalterno da hegemonia e o meio de fins que ignora ou the é proibido contestar, então 0 agente do saber prático transforma-se num monstro, quer dizer, num intelectual, que se mete no que é de sua conta [...] e de que os outros dizem que se mete no que não é de sua conta. (SARTRE, 1994, p. 29)

Para 0 autor, a tomada de consciência é fator imprescindível para transformar um técnico mero reprodutor de ideias em alguém capaz de apontar o dedo e questionar e propor questões. E esse fenômeno, explica Sartre, necessariamente se realiza "no nível de suas atividades profissionais e de sua função" (1994, p. 30).

Bobbio (1997) faz uma releitura da noção gramsciana de intelectual orgânico, dizendo que "todos nós, pelo fato de vivermos em uma sociedade em cujas lutas participamos, somos orgânicos no sentido de que somos portadores de certos valores contra outros, defendemos certos interesses contra outros [...]" (p. 87). Assim, ao enquadrar-se, ele mesmo como intelectual, 
falando na primeira pessoa e assumindo seu papel político de pensar sobre o mundo e sobre si mesmo, abre a possibilidade da constituição de classes de intelectuais pertencentes a grupos capazes de ir contra a visão hegemônica. Tais são sua crença e sua esperança, que, no entanto, não deixam de carregar certa dose de temor: 0 autor teme os excessos e radicalismos que podem acometer mesmo os intelectuais que estão contra o sistema dominante. Mais do que recuperar a credibilidade perdida diante do socialismo real, Bobbio acrescenta à tarefa intelectual 0 esforço em lutar contra "o demônio da violência que ameaça destruir tudo, a começar daquele pouco de democracia que fomos capazes de conquistar contra o fascismo [...]" (BOBBI0, 1997, p. 90). Para ele, um intelectual não pode isolar-se em si mesmo nem ficar preso na também isolante "ideologia dogmaticamente assumida e passivamente servida", mas sim assumir uma posição questionadora. Para isso, deve preservar sua missão de conhecedor e crítico da realidade, buscando, prioritariamente, a democracia como modo de atingir um mundo que não mais separe poderosos e enfraquecidos.

Em suma, a imagem do verdadeiro intelectual pode ser pintada pelas metáforas da cabeça que pensa, do olho que enxerga, da boca que denuncia, do dedo que aponta. São os que receberam (ou alcançaram) formação e possuem capacidade mental para criticar a tradição, formular perguntas sobre o que é incômodo, colocar em dúvida as rédeas e cabrestos, sugerir novas respostas, propor outros caminhos, clamar a mudança. 0 engajamento é sua principal característica. Ele não vive apenas fechado em seu gabinete fazendo críticas ao mundo externo, mas, com seu trabalho, envolve-se nas lutas para transformar as coisas que critica.

\section{Os intelectuais e a mídia}

É preciso ter em mente que as formulações sobre as diferentes classes de intelectuais mencionadas acima são de épocas em que as posições políticas se podiam claramente perceber e se opor; inclusive, o embate entre elas não se reduzia à luta de ideias, mas materializava-se em conflitos sangrentos, um dos quais o próprio Sartre tomou parte $^{2}$. Algumas dessas classificações, contudo, como nota Octavio Ianni (2000), já não estão adequadas para descrever a política e a atuação política no final do século XX. As formas de sociabilidade e a dinâmica das forças sociais estão alteradas não só quantitativamente, mas também qualitativamente. 0 trabalho, a cultura, 0 consumo, os mercados, a globalização, tudo isso altera as antigas estruturas de dominação e instaura um novo palco - "imenso, complexo e difícil" - para a Política e para as instituições 
"clássicas", que, em muitos sentidos começam a ser desafiadas e remodeladas (IANNI, 2000).

Num contexto em que posições políticas são facilmente identificadas, não é difícil apontar os intelectuais engajados de uma posição ou de outra. Contudo, quando os limites daquilo que era identificado como domínio e opressão ficam escondidos pela força invisível de um pensamento que se pretende universal, 0 intelectual (entendido como aquele que contesta, que critica, que questiona) parece ficar, em grande medida, desprovido de sentido. Diante do novo cenário político mundial pós queda do muro de Berlim e do espalhamento imperialista do neoliberalismo e da ditadura do mercado, a cabeça parece não pensar, a visão começa a ficar turva, a boca apenas balbucia, 0 dedo antes em riste não se sustenta diante das falanges enfraquecidas.

A pensadora argentina Beatriz Sarlo (1997) considera que aqueles que outrora pensaram ser capazes de mudar o mundo acreditavam ter uma missão pedagógica libertadora, sentiam-se representantes dos interesses dos desvalidos perante os poderosos, pensavam que sabiam mais que os outros... Esses constituíam uma certa figura de intelectual que acabou entrando em crise na contemporaneidade (1997, p. 165). No atual contexto em que um pensamento totalizador tenta se impor subrepticiamente como se fosse único e desejado, fazer críticas como os antigos intelectuais toma ares de loucura, insanidade ou baboseira. Assim, a própria ação de engajamento parece não mais fazer tanto sentido e os signos de intelectualidade já não são dados pela capacidade de pensar a realidade e elaborar questionamentos, mas passa a ser cotada por valores mensuráveis: cachês e presenças em conferências pelo mundo, premiações e condecorações, volume de recursos para 0 desenvolvimento de pesquisas, aclamações públicas na mídia. Esse é o tipo de reconhecimento direcionado àqueles que Sarlo chama de intelectuais eletrônicos, cujos saber e visibilidade estão dependentes do saber e do poder da mídia.

0 intelectual de maior evidência no mundo contemporâneo, sobretudo o mais visível nos grandes meios de comunicação, está longe de ser aquele pensador crítico que incomoda ou transgride. Ele é o agente do saber prático, o cientista, o especialista, que competentemente desenvolve tecnologias ou faz uso delas para alcançar a satisfação e a realização humanas. Entretanto, os parâmetros para que 0 ser humano se sinta realizado são ditados pela lógica consumista, pela sociedade do desperdício e da opulência, da satisfação prioritária do desejo individual em detrimento do benefício coletivo. Qualquer voz que se levante contra isso pode ser identificada como a de alguém que perdeu o juízo ou que não sabe 0 "verdadeiro" caminho para a felicidade. 
No mundo contemporâneo da globalização, a nova estratégia de guerra do grupo dominante é não enfrentar a oposição de frente; é esconder-se, eximir-se da responsabilidade pelo andamento das coisas ruins que acontecem, é fingir que não existe qualquer posição contrária à sua. Com o inimigo oculto, a oposição ficou carente de referências concretas. 0 turvamento da posição ideológica que se impôs como hegemônica acabou por enfraquecer o modelo clássico de intelectual engajado, pois quando não existe mais um opositor claro, é mais difícil ter alguém com quem estabelecer a postura de luta, de embate. Ora, diz, Edward Said, "para um intelectual que não está em atividade simplesmente para promover os interesses de outros, tem de haver oponentes que são considerados responsáveis pelo atual estado de coisas, antagonistas com os quais se deve embater diretamente" (SAID, 2004, p. 37). Quer dizer que, embora se possa considerar um desaparecimento das posições bem definidas e uma multiplicação de pontos de vista e bandeiras defendidas, isso não significa uma real democratização e 0 fim do sistema de dominação operado pelo capital.

Octavio Ianni, Edward Said e Beatriz Sarlo discutem a figura do intelectual a partir do contexto contemporâneo, de fim da Guerra Fria, abertura política, ampliação dos mercados em níveis mundiais, emergência de novas tecnologias de comunicação e informação, aceleração dos fluxos de trocas simbólicas e de mercadoria... Eles concordam que a nova organização desse mundo global tem sido terreno propício para a proliferação de discursos dos técnicos e cientistas (que se consagram como os intelectuais mais visíveis deste tempo), meramente reprodutores da nova ordem que se instaura como hegemônica. Mas Sarlo e Said fazem questão de frisar que a postura intelectual genuína não está necessariamente enterrada frente a essa realidade. As novas tecnologias de comunicação (SAID, 2004) e a arte crítica (SARLO, 2000) abrem brechas para uma ação intelectual nos nossos tempos

\section{0 jornalista na contemporaneidade}

Logo na abertura deste trabalho, pensava-se sobre os motivos que levam alguns jovens, hoje, a ingressar na faculdade para obter um diploma de jornalismo no Brasil. Como já mencionado, a imagem de intelectual está entre as representações da identidade jornalística, mas tendo refletido sobre o diagnóstico de Ianni, Said e Sarlo, sobrevem a questão: será que a nossa sociedade do fim do século XX e início de século XXI, fundada na centralidade da mídia e do mercado, dá espaço para motivação por um ideal ou carrega qualquer noção de engajamento?

Embora não esteja focado na questão da identidade jornalística, o pensador Edward Said faz uma análise das dificuldades de se exercer o papel do intelectual na contemporaneidade e acaba apontando para alguns rumos otimistas no que diz respeito à utilização das novas tecnologias de informação e comunicação como 
brechas ao poderio comunicativo e persuasivo das grandes corporações, governos e outros representantes do poder hegemônico.

[...] todos nós deveríamos trabalhar hoje tendo em mente a noção da existência de uma grande probabilidade de atingir públicos muito maiores do que poderíamos imaginar há uma década, embora as chances de manter esse público sejam, pela mesma moeda, bastante incertas. Isso não é simplesmente uma questão de otimismo da vontade: encontra-se na própria natureza da escrita atual. (SAID, 2004, p. 36)

Essa constatação é particularmente interessante para se pensar as formas de trabalho jornalístico na atualidade. Quando se pensa em mídia, normalmente a imagem que se tem é das grandes redes de televisão, de rádio, de veículos impressos. De fato, a profissionalização da atividade jornalística, bem como a construção de uma identidade mais sólida para esses trabalhadores enquanto categoria profissional estão, em grande medida, associadas a processos históricos de consolidação de algumas empresas, alguns veículos de comunicação, que constituíram e continuam a constituir referências para a prática jornalística no país. Os grandes veículos impressos, principalmente do Rio de Janeiro, inauguraram mudanças na imprensa brasileira da década de 1950 que foram sendo copiadas e adaptadas para outros veículos do Brasil. 0 estilo de jornalismo da Rede Globo, sobretudo do Jornal Nacional, estabeleceu muitos parâmetros para a prática dessa profissão no espaço da televisão. Seja no impresso, seja nos meios audiovisuais, a profissão de jornalista deveu, durante muitas décadas, sua imagem a um atrelamento às empresas, aos tradicionais meios de divulgação da informação jornalística. Mas, com o computador e a internet, esse atrelamento já não é tão automático. Os novos mecanismos de comunicação e interatividade possibilitam, como vê Said (2004), a abertura do âmbito dos produtores e dos públicos, e isso certamente também amplia as chances para 0 desenvolvimento de novas experimentações do jornalismo, não necessariamente submetidas à lógica da mídia tradicional.

A perspectiva otimista sobre as novas tecnologias e 0 ambiente virtual da internet não estão sustentadas por uma visão inocente. Nem este artigo nem Said (2004) desconsideram a existência dos mecanismos - invisíveis ou abertamente coercitivos usados por aqueles que procuram silenciar os intelectuais e abafar posturas combativas e críticas com sua força de homogeneização (ainda que travestida de multiplicidade).

Tendo exposto todas essas reflexões até aqui, e tendo o leitor acompanhado a descrição dos diferentes tipos de intelectuais, definindo-se inclusive 0 que seria 0 verdadeiro intelectual, é chegado o momento de retomar a pergunta inicial deste trabalho: que representações de intelectual estão presentes na construção da identidade jornalística?

Para dar essa resposta, não devemos nos esquecer de que, embora haja jornalistas 
trabalhando com assessoria de imprensa e há novas formas de comunicação sendo experimentadas com as novas tecnologias e absorvendo a mão de obra do jornalista, a identidade desse profissional ainda está fortemente marcada pela natureza do trabalho que é desenvolvido nos maiores veículos de comunicação. Então, isso deve ser levado em conta quando se pretende discutir a imagem desse profissional como intelectual.

Não é necessário muito esforço para vislumbrar, nas páginas da imprensa e nas telas dos programas jornalísticos, diversos jornalistas em constante contato com políticos e especialistas das mais diversas áreas de conhecimento. Em diversas situações, convivem com cientistas, acadêmicos, pesquisadores, ativistas políticos e outros intelectuais que podem ser do tipo "expertos" (BOBBI0, 1997), "técnicos do saber prático" (SARTRE, 1994), ou mesmo genuínos intelectuais (nos termos discutidos nos parágrafos anteriores). Como se viu com Sarlo, Ianni e Said, estes, para serem ouvidos no mundo contemporâneo, acabam tendo algum grau de dependência e necessidade em relação aos agentes que operam as esferas produtivas meios de comunicação. Assim, parte do que constitui a autoridade dos jornalistas é formada pela prerrogativa que eles têm de reproduzir essas vozes. Através dessa proximidade, alguns jornalistas têm sua grande chance de galgar sua própria imagem de intelectual. Mas isso, na visão de Bourdieu (1997), não lhes autoriza a se denominar como um deles.

Não se pretende discutir, aqui, se Bourdieu tem ou não razão de rejeitar que jornalistas possam ser intelectuais. 0 que está em questão é um processo de construção identitária, 0 qual se faz, necessariamente, pela projeção de representações. Tal como define Michael Pollak, de maneira bem objetiva e clara, construir identidade é procurar elementos capazes de construir uma imagem de si para si e para os outros (POLLAK, 2004). E os jornalistas, por terem na mídia seu principal local de visibilidade, é aí que se apresentam das maneiras que pretendem ser olhados.

Ao estar do lado de intelectuais, dirigindolhes perguntas, fazendo, eventualmente, comentários (caso o espaço jornalístico permita), equiparam-se, de alguma forma àqueles. No mínimo, mostram-se à altura de dialogar com os intelectuais. Mas, ao mesmo tempo, um dos princípios que ainda é bastante valorizado no meio jornalístico - a objetividade - opera um sentido de distanciamento, de "neutralidade", de isenção. Contudo, tal distanciamento ajuda a construir a imagem de intelectual para 0 jornalista na medida em que, com ela, ele se mostra competente - e neutro, portanto ético para traduzir ao grande público o que está longe de seu alcance. 0 mediador, então, é valorizado.

Tal como já afirmado anteriormente, a definição ordinária de intelectual está geralmente associada a ideias abrangentes: posse de 
"cultura", inteligência, estudo, acúmulo de saberes. Um perfeito estereótipo dessa figura seria senhor de óculos, distintamente vestido, sentado em uma biblioteca, com ar de sabe-tudo. Muito parecida à descrição dos repórteres "ratos de biblioteca ou caçadores de tesouros perdidos em sebos labirínticos [...]" (FAERMAN, 1997), presente no livro em que Audálio Dantas recolhe memórias de jornalistas. 0 estudioso, 0 esforçado, 0 dedicado às leituras e outras representações do gênero estão ligadas às ideias de competência e posse de um saber pela realização de algum tipo de atividade, critérios muito semelhantes aos da classificação de Gramsci (1988) dos "intelectuais tradicionais", cuja existência funda-se numa distinção feita dos membros desse grupo em relação aos outros.

A imagem do jornalista como um intelectual nesse sentido não deriva tanto do talento ou competência que podem demonstrar em relação ao seu próprio trabalho, sua própria técnica, mas a outros saberes. Não se vê uma aclamação pública do caráter intelectual do jornalista por sua destreza em produzir um lide, ou pela sua boa diagramação, ou por uma bela tomada de câmera, ou pela sua capacidade de entender a diferença entre redigir um editorial, um artigo ou uma resenha. Não são esses atributos ligados diretamente à ordem técnica do trabalho jornalístico que estão refletidos na sua imagem de intelectual. Esta se torna evidente quando se valoriza a quantidade de conhecimentos que 0 jornalista tem em outras áreas de conhecimento. Em outras palavras: a habilidade intelectual do jornalista fia-se num suposto pluralismo, ou melhor, na capacidade que ele tem de poder falar com propriedade sobre qualquer assunto e poder transitar por várias áreas de conhecimento ${ }^{3}$.

A definição gramsciana de intelectuais tradicionais serve para pensar uma das maneiras de lidar com a imagem de intelectual no processo de construção da identidade jornalística, uma vez que ficou demonstrado que ela está marcada pelo reconhecimento concedido a um grupo pela sua distinção em virtude de seus saberes. De acordo com tal critério de notoriedade, é fácil perceber 0 quanto o cultivo de uma imagem de intelectual nesse sentido de distinção pelo saber favorece a autoridade do jornalista e continua sendo reiteradamente agregada à sua identidade. Já a categoria "intelectual orgânico" já não serve tanto para pensar a projeção de uma imagem explícita do jornalista como intelectual, mas é um conceito de extrema pertinência para sistematizar

Isso é ilustrado com as memórias do jornalista Pery Cotta, que no livro Calandra: o sufoco da imprensa nos anos de chumbo (1997), relembra, com a seguinte descrição, seus momentos no jornal Correio da Manhã (Rio de Janeiro) durante a ditadura militar iniciada em 1964 no Brasil: "Em Redação de jornal, na época anterior ao diploma universitário, o que não faltava era médico, engenheiro, advogado e outros profissionais para dar toda e qualquer orientação. A maioria tinha um ou mais cursos superiores. Se o repórter saía para cobrir um julgamento, um acidente em viaduto ou a hospitalização de uma personagem, sabia exatamente o que perguntar. E, mais do que isto, usava a terminologia própria do entrevistado e parecia senhor absoluto da questão. Um banho de competência [...]" 
críticas a alguns modos de atuação dos jornalistas, principalmente aqueles que prestam seus serviços às grandes corporações midiáticas.

Gramsci enfatiza a capacidade dos intelectuais orgânicos em lidar com ideias e operar como organizadores da cultura, a serviço de algum grupo ou classe. Em muitas de suas manifestações, principalmente na chamada mídia de massa, o jornalismo funciona exatamente como uma plataforma na qual seus agentes contribuem para consolidar a hegemonia do grupo dominante ${ }^{4}$. Sua contribuição para a formação de mentalidades já está, em potência, no poder que possuem para definir a agenda de assuntos a serem veiculados na mídia. Segundo teóricos da teoria da agenda setting, "tanto a seleção de objetos que despertam a atenção como a seleção de enquadramentos para pensar esses objetos são poderosos papéis do agendamento" (McCOMBS; SHAW, 1993, p. 62 apud TRAQUINA, 2001, p. 33).

0 poder de formar mentalidades e transmitir conhecimentos, bem como o lugar de atuação de muitos intelectuais que lidavam com esses saberes esteve tradicionalmente ligado às clássicas instâncias do saber (escola, igreja, institutos de pesquisa). Na sociedade midiatizada, o discurso jornalístico é, em grande medida, quem fornece explicações sobre 0 mundo e tais falas são dirigidas a um grande espectro de leitores, ouvintes, telespectadores e internautas. Em vez de exercerem um trabalho circunscrito aos muros de uma ou outra instituição (a escola, o partido, o órgão público, a Justiça), os jornalistas têm suas vozes amplificadas pela mídia e, na própria dinâmica de seu trabalho, ocupam grande parte do terreno do discurso público. É exatamente aí que constroem a sua identidade como intelectuais. Vale lembrar: os jornalistas ocupam, sim, o terreno, mas não são seus donos.

Os donos dos principais setores de mídia no Brasil coincidem ou estão unidos com os donos do pensamento dominante e, nesse cenário, a arena midiática carrega a marca do mundo contemporâneo, a supremacia do capital exploratório e do lucro a qualquer custo em detrimento de valores humanos de ordem não material.

0 que singulariza a grande corporação de mídia é que ela realiza limpidamente a metamor-

As autoras Sônia Regina Mendonça e Marialva Barbosa comentam no artigo "Estado e Comunicação no Brasil: em torno do pensamento de Gramsci” (2006) que os jornalistas desempenharam papéis significativos na propagação de ideias favoráveis aos poderosos em diversos momentos da história do Brasil. Elas comentam que "na passagem da Monarquia para a República, a ação da imprensa e dos jornalistas foi fundamental no Rio de Janeiro para construir a ideia desse progresso, como passagem do atraso para a civilização" (MENDONÇA; BARBOSA, 2006). No Estado Novo, a imprensa ajudou a difundir e consolidar a construção ideológica do regime estadonovista. "Também em outro período de exceção na história mais recente do país - os governos ditatoriais militares - a ação dos meios de comunicação é fundamental para construir um outro ideal de modernidade e possibilitar 0 que Gramsci chama a prática do transformismo. 0 Estado substitui os grupos sociais na função de dirigir uma luta de renovação. E a imprensa, como parte integrante desse estado e como partido dos grupos dominantes e hegemônicos, difundirá mais uma vez a mítica da modernidade como indispensável para a construção de uma nova face para o país, inserido numa fase do capitalismo mundial" (MENDONÇA; BARBOSA, 2006). 
fose da mercadoria em ideologia, do mercado em democracia, do consumismo em cidadania. Realiza limpidamente as principais implicações da indústria cultural, combinando a produção e a reprodução cultural com a produção e reprodução do capital; e operando decisivamente na formação de 'mentes' e 'corações', em escala global (IANNI, 2000)

Embora tenham grande reconhecimento e visibilidade, os jornalistas não detêm a posse da arena midiática, mas são funcionários dela. 0s que trabalham nos grande conglomerados da mídia no Brasil podem se questionar se o papel que desempenham ali dentro poderia ter algum respaldo, alguma ação intelectual, algum impacto de intelectual engajado. Mesmo os jornalistas que fazem oposição ao sistema de dominação neoliberal devem estar cientes de que os textos e imagens que produzem estão sujeitos a filtragens e coerções por parte da empresa onde trabalham. Por mais esforço que coloquem em escutar todos os lados envolvidos, em tratar com cuidado e contextualizadamente os depoimentos das fontes, ainda correm o risco de ver na edição veiculada ao público o acréscimo de um título tendencioso, o corte de alguns parágrafos, a mudança na ordem de apresentação das entrevistas, a adição de imagens (fotos ou vídeo) de arquivo não relacionadas diretamente à matéria, um modo diagramático de apresentação que leva a uma super ou subvalorização do assunto...

A profissão está revestida de um certo sentimento de "missão". Em depoimento ao CPDOC (ABREU; LATTMAN-WELTMAN; ROCHA, 2003), o jornalista
Augusto Nunes, diretor de redação que comandou reformas no jornal O Estado de S. Paulo na virada dos anos 1980 para 90, expressa essa crença:

[...] acho que devemos tratar de política, para que o povo brasileiro seja menos despolitizado. Há coisas que a imprensa deve considerar uma missão a cumprir; em relação às quais ela deve tratar de fazer a cabeça das pessoas. [...] Se for o caso, um jornal deve contrariar a maioria. Não pesquisei 0 assunto, mas imagino que algum jornal tenha feito campanha em favor da vacinação obrigatória quando a maioria absoluta não aceitava aquilo (ABREU LATTMAN-WELTMAN; ROCHA, 2003, p. 343).

A mobilização das ideias de prestação de serviço para a produção do bem-comum e 0 engajamento com os interesses da sociedade, além de produzir uma imagem de intelectual engajado, reforça a credibilidade do jornalista para fazer críticas contra outros agentes sociais. Entretanto, o que se pode acompanhar nos produtos jornalísticos das grandes corporações de mídia é que frequentemente a crítica deixa de ser feita. Nem sempre os jornalistas exercem um papel de intelectual genuíno, sendo, em diversas situações, principalmente na chamada grande mídia, mais adequadamente caracterizados como intelectuais orgânicos dos grupos dominantes ou, para dizer com Sartre, simples "servidores da hegemonia", meros funcionários das empresas que temem pelos seus empregos e que não passam de técnicos do saber prático.

A atuação orgânica ganha forte aliado com 0 ideal da objetividade. Ele é particularmente útil no desempenho desse papel. Pretensamente, os 
jornalistas dão ao público aquilo que a sociedade compartilha como valores "universais". Portanto, uma vez que se defende algo que está situado acima de interesses particulares, a objetividade do jornalista serve para sustentar uma certa imagem positiva e confiável desses profissionais, além de reforçar a crença de que, por vocação, "seu objeto primordial não é difundir aquilo que governos, igrejas, grupos econômicos ou políticos desejam contar ao público, [...], mas aquilo que 0 cidadão quer, precisa e tem 0 direito de saber, o que não necessariamente coincide com o que os outros querem contar" (BUCCI, 2000, p. 42).

Mas não podemos olhar para 0 jornalista apenas com críticas desse tipo como se eles nunca tivessem agido com uma vinculação intelectual engajada. Embora não com a força do grande capital, é possível encontrar algumas publicações $^{5}$ que fogem ao padrão de jornalismo das grandes corporações e que representam espaço para manifestação mais engajada $\mathrm{e}$ autônoma do intelectual jornalista, bem como abrem espaço para a expressão de outros intelectuais cujas vozes dificilmente são ouvidas na grande mídia.

Quando se pensa sobre a identidade jornalística no mundo contemporâneo, é de grande valor, ainda, retomar o que pensa Edward Said (2004) e analisar o potencial democrático que pode ser explorado a partir da internet, dos novos fluxos de informação e comunicação em níveis globais.

É interessante deixar claro, porém, que o processo de construção da identidade é complexo e permeado por contradições como esta: a marcante atuação orgânica por parte grande dos jornalistas, sob forma de apoio e reprodução (por vezes abertos e declarados, outras vezes velados) dos interesses dos grupos dominantes, em contraste com a imagem de profissionais combativos, que estão interessados em informar a sociedade e contribuir para o bem comum.

\section{Referências}

ABREU, Alzira Alves de; LATTMAN-WELTMAN, Fernando; ROCHA, Dora (orgs.). Eles mudaram a imprensa: depoimentos ao CPDOC. Rio de Janeiro: Fundação Getulio Vargas, 2003.

BOBBIO, Norberto. Os intelectuais e o poder: dúvidas e opções dos homens de cultura na sociedade contemporânea. São Paulo: Unesp, 1997.

BOURDIEU, Pierre. Sobre a televisão. Rio de janeiro: Jorge Zahar, 1997.

BUCCI, Eugenio. Sobre ética e imprensa. São Paulo: Companhia das letras, 2000.

CHAUÍ, Marilena. "Intelectual engajado: uma figura em extinção?". In NOVAES, Adauto. 0 silêncio dos intelectuais. São Paulo: Cia das Letras, 2006.

COTTA, Pery. Calandra: o sufoco da imprensa nos anos de chumbo. Rio de Janeiro: Bertrand Brasil, 1997. 
FAERMAN, Marcos. A longa aventura da reportagem. In: DANTAS, Audálio (org.). Repórteres. São Paulo: Senac, 1997.

GRAMSCI, Antonio. Os intelectuais e a organização

da cultura. Rio de Janeiro: Civilização Brasileira, 1988.

Cadernos do cárcere: os intelectuais: 0

princípio educativo: jornalismo. Rio de Janeiro:

Civilização Brasileira, 2000. v. 2.

IANNI, Octavio. 0 príncipe eletrônico. In: IANNI, Octavio. Enigmas da modernidade-mundo. Rio de Janeiro: Civilização Brasileira, 2000.

LOPES, Fernanda Lima. Auto-referenciação e construção da identidade jornalística. Dissertação (Mestrado em Comunicação) - Escola de Comunicação, Universidade Federal do Rio de Janeiro, Rio de Janeiro, 2007.

MENDONÇA, Sonia Regina; BARBOSA, Marialva.

Estado e comunicação no Brasil: em torno do pensamento de Antonio Gramsci. In: ENCONTRO DE HISTÓRIA DA MÍDIA DA REDE ALFREDO DE CARVALHO, 4., 2006, São Luís. Anais... São Luis: Rede Alfredo de Carvalho, 2006. CD-ROM.

POLLAK, Michael. Memória e identidade social.

Estudos Históricos, Rio de Janeiro, v. 5, n. 10, p. 200215, 1992.

SAID, Edward. 0 papel público de escritores e intelectuais. In: MORAES, Dênis de (org.). Combates e utopias: os intelectuais em um mundo em crise. Rio de Janeiro: Record, 2004.

SARLO, Beatriz. A voz universal que toma partido. In: MORAES, Dênis de (org.). Combates e utopias: os intelectuais em um mundo em crise. Rio de Janeiro: Record, 2004. Intelectuais. In: Cenas da vida pósmoderna. Rio de Janeiro: UFRJ, 2000.

SARTRE, Jean Paul. Em defesa dos intelectuais. São Paulo: Ática, 1994.
TRAQUINA, Nelson. 0 estudo do jornalismo no

século XX. São Leopoldo: Unisinos, 2001. 
Meanings of intellectual image for journalists' identity construction

\section{Abstract}

Although Gramsci and Bourdieu resist in considering a journalist an intellectual, journalistic identity has frequently been characterized by such notion. This paper deals with the different types, classes and concepts of intellectual forged by authors such as Sartre, Gramsci and Bobbio. Moreover, as this paper is concerned with the role of intellectuals' image in journalistic identity in the contemporary world, it is important to reflect upon the connections between different kinds of intellectuals and new information and communication technologies. This task counts on contributions given by authors such as Said, Sarlo, Ianni and others.

\section{Keywords}

Journalist. Intellectual. Identity.

\section{Significados de la imagen de intelectual en la construcción de la identidad de los periodistas}

\section{Resumen}

Aunque Gramsci y Bourdieu resistan en considerar intelectuales a los periodistas, hay en la identidad de ellos rasgos que los clasifican de este modo. Este trabajo pone la cuestión sobre qué tipo de intelectuales son los periodistas, puesto que bajo eso hay distintas categorías y clasificaciones, desarrolladas por autores clásicos como Sartre, Gramsci y Bobbio. Además, al tratar de la imagen de intelectual en la construcción de la identidad del periodista en el mundo contemporáneo, es importante considerar el lugar y el papel del intelectual ante las nuevas tecnologías de información y comunicación, lo que tiene base en reflexiones de autores como Edward Said, Beatriz Sarlo y Octavio Ianni.

\section{Palabras clave}

Periodista. Intelectual. Identidad. 


\section{Expediente}

A revista E-Compós é a publicação científica em formato eletrônico da Associação Nacional dos Programas de Pós-Graduação em Comunicação (Compós). Lançada em 2004, tem como principal finalidade difundir a produção acadêmica de pesquisadores da área de Comunicação, inseridos em instituições do Brasil e do exterior.
E-COMPÓS I www.e-compos.org.br I E-ISSN 1808-2599

Revista da Associação Nacional dos Programas de Pós-Graduação em Comunicação. Brasília, v.12, n.3, set./dez. 2009.

A identificação das edições, a partir de 2008 passa a ser volume anual com três números.

\section{CONSELHO EDITORIAL}

Afonso Albuquerque

Universidade Federal Fluminense, Brasil

Alberto Carlos Augusto Klein

Universidade Estadual de Londrina, Brasi

Alex Fernando Teixeira Primo

Universidade Federal do Rio Grande do Sul, Brasil

Alfredo Vizeu

Universidade Federal de Pernambuco, Brasi

Ana Carolina Damboriarena Escosteguy

Pontifícia Universidade Católica do Rio Grande do Sul, Brasil

Ana Silvia Lopes Davi Médola

Universidade Estadual Paulista, Brasil

André Luiz Martins Lemos

Universidade Federal da Bahia, Brasil

Ângela Freire Prysthon

Universidade Federal de Pernambuco, Brasil

Antônio Fausto Neto

Universidade do Vale do Rio dos Sinos, Brasil

Antonio Carlos Hohlfeldt

Pontifícia Universidade Católica do Rio Grande do Sul, Brasil

Arlindo Ribeiro Machado

Universidade de São Paulo, Brasil

César Geraldo Guimarães

Universidade Federal de Minas Gerais, Brasi

Cristiane Freitas Gutfreind

Pontifícia Universidade Católica do Rio Grande do Sul, Brasil

Denilson Lopes

Universidade Federal do Rio de Janeiro, Brasil

Eduardo Peñuela Cañizal

Universidade Paulista, Brasil

Erick Felinto de Oliveira

Universidade do Estado do Rio de Janeiro, Brasil

Francisco Menezes Martins

Universidade Tuiuti do Paraná, Brasil

Gelson Santana

Universidade Anhembi/Morumbi, Brasil

Goiamérico Felício

Universidade Federal de Goiás, Brasil

Hector Ospina

Universidad de Manizales, Colômbia

Herom Vargas

Universidade Municipal de São Caetano do Sul, Brasil

leda Tucherman

Universidade Federal do Rio de Janeiro, Brasil

Itania Maria Mota Gomes

Universidade Federal da Bahia, Brasil

Janice Caiafa

Universidade Federal do Rio de Janeiro, Brasil

Jeder Silveira Janotti Junior

Universidade Federal da Bahia, Brasil

\section{João Freire Filho}

Universidade Federal do Rio de Janeiro, Brasil

John DH Downing

University of Texas at Austin, Estados Unidos

José Luiz Aidar Prado

Pontifícia Universidade Católica de São Paulo, Brasil

José Luiz Warren Jardim Gomes Braga

Universidade do Vale do Rio dos Sinos, Brasi

Juremir Machado da Silva

Pontifícia Universidade Católica do Rio Grande do Sul, Brasil

Lorraine Leu

University of Bristol, Grã-Bretanha

Luiz Claudio Martino

Universidade de Brasília, Brasil

Maria Immacolata Vassallo de Lopes

Universidade de São Paulo, Brasil

Maria Lucia Santaella

Pontifícia Universidade Católica de São Paulo, Brasil

Mauro Pereira Porto

Tulane University, Estados Unidos

Muniz Sodre de Araujo Cabral

Universidade Federal do Rio de Janeiro, Brasil

Nilda Aparecida Jacks

Universidade Federal do Rio Grande do Sul, Brasil

Paulo Roberto Gibaldi Vaz

Universidade Federal do Rio de Janeiro, Brasil

Renato Cordeiro Gomes

Pontifícia Universidade Católica do Rio de Janeiro, Brasil

Ronaldo George Helal

Universidade do Estado do Rio de Janeiro, Brasil

Rosana de Lima Soares

Universidade de São Paulo, Brasil

Rossana Reguillo

Instituto Tecnológico y de Estudios Superiores do Occidente, México

Rousiley Celi Moreira Maia

Universidade Federal de Minas Gerais, Brasil

Samuel Paiva

Universidade Federal de São Carlos, Brasil

Sebastião Albano

Universidade Federal do Rio Grande do Norte, Brasil

Sebastião Carlos de Morais Squirra

Universidade Metodista de São Paulo, Brasil

Simone Maria Andrade Pereira de Sá

Universidade Federal Fluminense, Brasi

Suzete Venturelli

Universidade de Brasília, Brasil

Valério Cruz Brittos

Universidade do Vale do Rio dos Sinos, Brasil

Veneza Mayora Ronsini

Universidade Federal de Santa Maria, Brasil

Vera Regina Veiga França

Universidade Federal de Minas Gerais, Brasi

\section{COMISSÃO EDITORIAL}

Felipe da Costa Trotta I Universidade Federal de Pernambuco, Brasil Rose Melo Rocha I Escola Superior de Propaganda e Marketing, Brasil

\section{CONSULTORES AD HOC}

Arthur Autran Franco de Sá Neto I Universidade Federal de São Carlos

Carlos Eduardo Franciscato I Universidade Federal de Sergipe

Elisa Reinhardt Piedras I Universidade Federal do Rio Grande do Su

Elizabeth Bastos Duarte I Universidade Federal de Santa Maria

Marcia Benetti Machado I Universidade Federal do Rio Grande do Sul

Sandra Maria Lúcia Pereira Gonçalves I Universidade Federal do Rio Grande do Sul

Suzana Kilpp I Universidade do Vale do Rio dos Sinos

Tattiana Gonçalves Teixeira I Universidade Federal de Santa Catarina

Vander Casaqui I Escola Superior de Propaganda e Marketing

Vicente Gosciola I Universidade Anhembi Morumbi

Walter Teixeira Lima Junior I Fundação Cásper Líbero

REVISÃO DE TEXTO E TRADUÇÃO I Everton Cardoso

EDITORAÇ̃̃ ELETRÔNICA I Raquel Castedo
COMPóS I www.compos.org.br

Associação Nacional dos Programas de Pós-Graduação em Comunicação

Presidente

Itania Maria Mota Gomes

Universidade Federal da Bahia, Brasil

itania@ufba.br

Vice-presidente

Julio Pinto

Pontifícia Universidade Católica de Minas Gerais, Brasil

juliopinto@pucminas.br

Secretária-Geral

Ana Carolina Escosteguy

Pontifícia Universidade Católica do Rio Grande do Sul, Brasil

carolad@pucrs.br 